\title{
Introduction to the National Mineral Deposit Database of China (2020)
}

\subsection{Background}

The National Mineral Deposit Database of China (2002) (also referred to as the Database 2002) has been ranking top in terms of daily data distribution volume in the National Geological Archives of China (also referred to as the NGAC). However, it cannot be updated in a sustainable manner and cannot provide up-to-date, comprehensive data at present. Therefore, a new edition of the database is urgently needed by the industry of mineral geological survey and social users. To this end, the NGAC is committed to vigorously promoting the development and utilization of mineral-related geologic data holdings and comprehensively integrating mine-related geologic data. In addition, it has also made great efforts to study the update and maintenance mechanisms of mineral deposit data and produce thematic mineral deposit data to serve the needs of all parties. The purpose is to provide support for mineral geological survey, prospecting prediction, and research on metallogenic rules. Meanwhile, it has strived to comprehensively improve the informatization of geological survey and information service level through deep data mining of mineral-related geologic data. The aims are to meet the growing demand of mining industry development for mineral-related geologic data, to provide rich and reliable geologic data for economic and social development, to provide scientific and reliable research and assessment results for government decision-making, and to provide the most comprehensive mineral resource information for mining service fields.

\subsection{Method}

Geologic data contain a great deal of geological knowledge, which especially includes the information of mineral deposits. According to statistics of the data holdings of the NGAC, mineral exploration data account for more than $60 \%$ of all data holdings. In addition, the regional mineral survey data and geological scientific research data in regional survey data also contain a large amount of mineral deposit information. All these provide data sources for the building of a new edition of the National Mineral Deposit Database of China.

A new edition of the database is a comprehensive professional database established based on the Database 2002. The establishment process is as follows. The mineral deposit data are first mined from the mineral-related data holdings of the NGAC using the big data mining technology. Afterwards, the data are cleaned, sorted, integrated, extracted, converged, and input into the database (Fig. 1.1). It can be continuously updated and thus can dynamically reflect the up-to-date state of the mineral resources in China.

To serve the needs of social and economic development while still being built, a new edition of the database will be established once every year. 


\section{Knowledge sources}

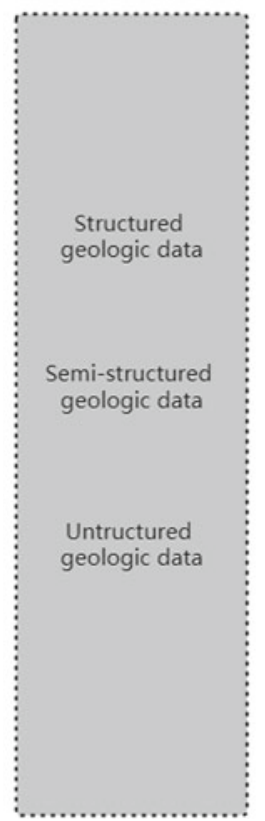

Tectonic elements
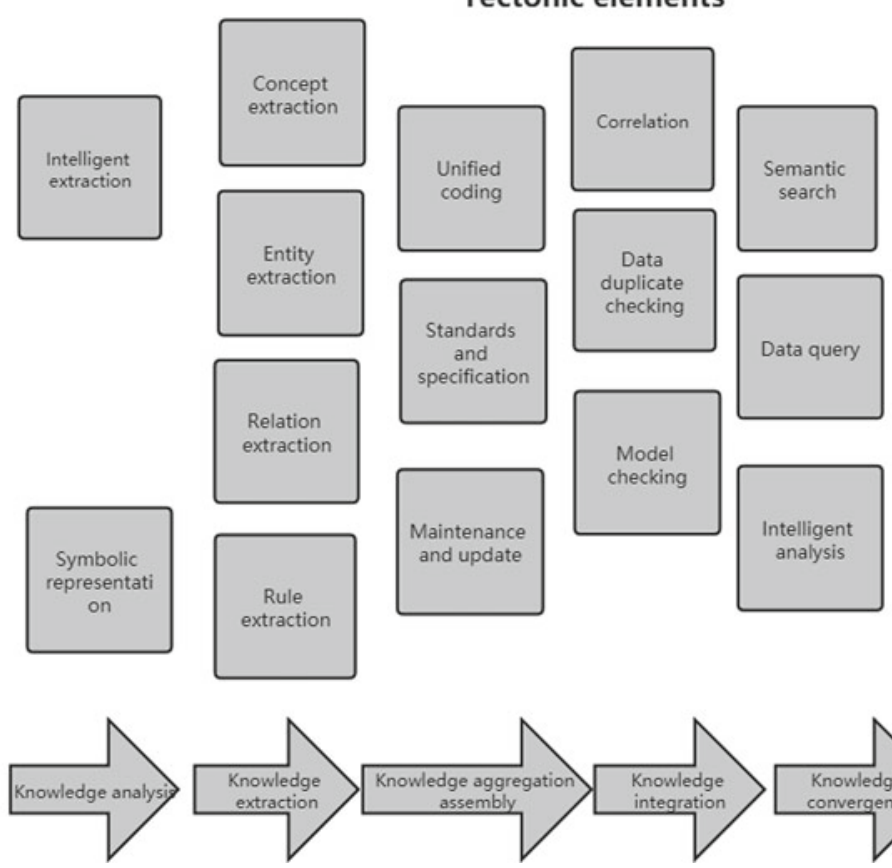
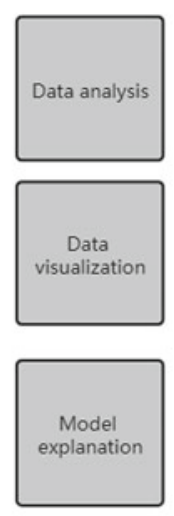

A new edition of

the National

Mineral Deposit

Database of China:

Fig. 1.1 Method of building a new edition of the National Mineral Deposit Database of China

Open Access This chapter is licensed under the terms of the Creative Commons Attribution 4.0 International License (http://creative commons.org/licenses/by/4.0/), which permits use, sharing, adaptation, distribution and reproduction in any medium or format, as long as you give appropriate credit to the original author(s) and the source, provide a link to the Creative Commons license and indicate if changes were made.
The images or other third party material in this chapter are included in the chapter's Creative Commons license, unless indicated otherwise in a credit line to the material. If material is not included in the chapter's Creative Commons license and your intended use is not permitted by statutory regulation or exceeds the permitted use, you will need to obtain permission directly from the copyright holder. 